\title{
STUDY OF CNS EFFECTS OF MACROLIDE ANTIBIOTICS: AN EXPERIMENTAL STUDY
}

\author{
J. B. Deshmukh, S. B. Tamboli
}

1. Assistant Professor, Department of Pharmacology, Dr. S C Govt. Medical College, Nanded

2. Associate Professor \& Head, Department of Pharmacology, Dr. S C Govt. Medical College, Nanded

\section{CORRESPONDING AUTHOR}

Dr. J. B. Deshmukh

Dept of Pharmacology

Dr. Shankarrao Chavan Govt. Medical College,

Nanded - 431602, Maharashtra.

E-mail: drmangesh4u@yahoo.com

Ph: 00919921986234.

\begin{abstract}
Macrolides are an old, well established class of antibacterial agents which play an important role in the management of infectious diseases. The present study was undertaken to study the CNS effects of some of the macrolides antibiotics namely erythromycin, clarithromycin, azithromycin and roxithromycin in rats. 30 healthy adult albino rats of either sex of Haffkine's strain weighing 100-200g were used for the study. Each group consists of six animals. Various tests were used for screening of drugs on CNS activity. Amongst the macrolides namely erythromycin claritromycin, azithromycin and roxithromycin, only roxithromycin showed CNS depressant activity in rats. Similarly only roxithromycin and azithromycin showed anti-inflammatory property.
\end{abstract}

KEY WORDS: Macrolides, CNS effects, Experimental study, Rat

INTRODUCTION: Macrolides are an old, well established class of antibacterial agents which play an important role in the management of infectious diseases.

Macrolide antibiotics are so named because they contain a many membered lactone ring to which one or more deoxy sugars are attached.

Erythromycin, its prototype member was discovered in 1952. In an attempt to overcome limitation of Erythromycin like narrow spectrum and some pharmacokinetic drawbacks, number of semi synthetic macrolides have been produced namely, roxithromycin, clarithromycin, azithromycin, spiramycin, dirithromycin etc. ${ }^{1}$

The renewed interest in macrolides antibiotics with expanded indications for clinical use as well as their markedly increased usages justifies the continuous search for new compounds designed to offer the patients not only enhanced bio-availability but also a reduced incidence of adverse effects.

Adverse reactions to macrolides mainly relates to GIT and skin. However some of the CNS related adverse effects are also reported possible due to use of large dose for long period of time and as a drug interaction. ${ }^{2}$

Some sporadic cases of CNS effects like dizziness, transient deafness, delirium, apparent fatigue, disorientation, have been reported during monotherapy. ${ }^{3}$

Very few studies have been done to study the CNS related effects of macrolides antibiotics. 
With this background, the present study was undertaken to study the CNS effects of some of the macrolides antibiotics namely erythromycin, clarithromycin, azithromycin and roxithromycin in rats.

MATERIAL AND METHODS: Healthy adult albino rats of either sex of Haffkine's strain weighing 100-200g were used for the study. They were allowed free access to diet and water.

This study and was conducted at department of pharmacology, SRTR Medical College, Ambajogai. The study was approved by the institutional animal ethical committee.

30 rats were divided into five groups. In each group six animals were given following drugs. erythromycin $-750 \mathrm{mg} / \mathrm{kg}$, clarithromycin $-100 \mathrm{mg} / \mathrm{kg}$, azithromycin- $50 \mathrm{mg} / \mathrm{kg}$ and roxithromycin $-30 \mathrm{mg} / \mathrm{kg}$

Drugs were dissolved in sterile water immediately before use. The usually used single dose of each drug in human was extrapolated to rats by using the dose conversion table based on body surface area. ${ }^{4}$

Substances affecting CNS may have a variety of manifestations since CNS activities vary according to part of the nervous system affected and degree of depression, the screening is non-specific. The following are most commonly used tests for screening of drugs on CNS activity. ${ }^{5}$

1. General behavioural test.

2. Motor co-ordination tests

Rota rod test,

Inclined plane test.

3. Pentobarbitone sleeping time

4. Special tests for detection of -

Analgesic activity,

Anti-inflammatory activity,

Anti-convulsant activity.

Statistical Analysis was done by using paired t test. The statistical significance was considered as $\mathrm{P}<0.05$.

RESULTS: GENERAL BEHAVIOURAL TEST: The test drugs did not produce any change in parameters like salivation lacrimation, defecation, respiratory rate.

MOTOR COORDINATION TEST: Roxithromycin only showed significant decrease in locomotor activity in inclined plane test. In rotating rod test the fall of time was significantly reduced in roxithromycin treated group of rats.

CONDITIONED AVOIDANCE RESPONSE: In this test only roxithromycin among test drugs was able to alter the response significantly.

PENTOBARBITONE SLEEPING TIME: Roxithromycin only significantly prolonged the sleeping time produced by pentobarbitone.

ANTICONVULSANT ACTIVITY: Roxithromycin reduced the duration of extensor response significantly in electrically induced convulsions. 
ANTIINFLAMMATORY ACTIVITY: Azithromycin and roxithromycin were able to significantly reduce carrageenin induced oedema.

ANALGESIC ACTIVITY: None of the macrolides antibiotics showed analgesic activity

DISCUSSION: Recent research into macrolides anti-bacterials has led to the discovery of a number of compounds with greatly improved potency, spectrum and clinical efficacy. These drugs may cause gastrointestinal and central nervous system adverse reaction but these are usually mild and self limiting and rarely require withdrawal of therapy.

Result of present experimental study for evaluating central nervous system related activity of some of the macrolides antibiotics namely erythromycin, clarithromycin, azithromycin and roxithromycin using a battery of tests showed that only roxithromycin significantly shown to have CNS depressant activity. However roxithromycin did not show any significant analgesic activity. Roxithromycin as well as azithromycin also showed significant anti-Inflammatory property in this study.

Acute mild hypothermia, ataxia, somnolence and apparent fatigue have been reported by Hassel B. (1994) ${ }^{6}$ in patients treated with macrolide antibiotics.

Manuel and others (1998) ${ }^{7}$ have shown that roxithromycin was found to reach very high concentration in the human brain suggesting it is extremely effective in crossing the blood brain barrier, where as no other macrolides are known to behave similarly.

Shibata U. et. Al (1981) ${ }^{8}$ have investigated a new macrolides antibiotic miocamycin (MOM) in mice, rats and rabbits after oral administration. MOM caused a decreased in spontaneous motor activity, increase of maximal electroshock seizure threshold. However no effect on general behaviour, inclined plane test, rota rod performance, thiopental induced sleep and conditioned avoidance response.

Angela Lanare et.al. have shown that macrolides posses anti-inflammatory activity in addition to antibacterial activity. Macrolides have been shown to affect several pathways of the inflammatory processes such as the migration of neutrophils, the oxidative stress in phagocytes and the production of proinflammatory cytokines. ${ }^{9}$

The anti-inflammatory activity of roxithromycin have been shown to be due to reduce production of nitric oxide (NO) and super oxide dismutase activity (Agen c. et. Al, 1993). ${ }^{10}$

Anti-inflammatory activity shown in our study to roxithromycin and azithromycin is in accordance with the above studies.

However more detailed and extensive experimental studies would be required to substantiate these findings.

ACKNOWLEDGEMENT: The author is thankful to Dr. Muhammed Mateenuddin, Professor and Head, Dept. of Pharmacology, Bidar Institute of Medical Sciences, Bidar (Karnataka) for his kind help.

\section{REFERENCES:}

1. Tripathi KD: Essentials of Medical Pharmacology. Macrolide antibiotics. 6th ed. New Delhi: Jaypee Brothers Medical Publishers; 2008:727-38.

2. Jiménez-Pulido I, Navarro-Ruiz A, Sendra P, et al. Hallucinations with therapeutic doses of clarithromycin. Int J Clin Pharmacol Ther. 2002;40:20-2. 
3. Pijlman AH, Kuck EM, van Puijenbroek EP, et al. Acute delirium, probably precipitated by clarithromycin. Ned Tijdschr Geneeskd 2001;145:225-8.

4. Ghosh MN. Fundamentals of experimental pharmacology. 4th ed. Kolkata, Hilton \& company, 2008:178.

5. Medhi B, Prakash A. Animal experiment On CNS. In practical manual of experimental and clinical pharmacology. New Delhi Jaypee Brothers Medical Publishers; 1st ed. 2010: 183-203

6. Hassel B. Acute hypothermia and adverse effect of CNS during erythromycin therapy. Tidsskr, Norlageoforen 1994:2010; 114(15):1696

7. Manuel, $\mathrm{C}$ and others. Penetration of roxithromycin into brain tissue. Program and Abstracts of the Twenty-Eighth Interscience Conference on Antimicrobial Agents and Chemotherapy, 1988; 1224, 23-26

8. Shibata U, Yamaki Y, Asaoka H, Sugiyama S, Takeda U, Nishimori T et al. General pharmacological studies on a new macrolide antibiotic, miokamycin (MOM). Jpn J Antibiot. 1981;34(5):734-46.

9. Ianaro A., Ialenti A., Maffia P., Sautebin L., Rombola L.,Carnuccio R. et al. Antiinflammatory activity of macrolide antibiotics. J. Pharmacol. Exp. Ther. 2000; 292:156163.

10. Agen C, Danesi R, Blandizzi C, Costa M, Stacchini B, Favini P, et al. Macrolide antibiotics as antiinflammatory agents: Roxithromycin in an unexpected role. Agents Actions 1993; 38:85-90.

Table No.1: Effect of macrolide antibiotics on Central nervous system using various test in rats.

\begin{tabular}{|c|c|c|c|c|c|c|c|c|c|}
\hline \multirow[t]{2}{*}{$\begin{array}{l}\text { Gr } \\
\text { ou } \\
\text { ps }\end{array}$} & \multirow[t]{2}{*}{$\begin{array}{l}\text { Treatment } \\
\text { (Dose mg/Kg) }\end{array}$} & \multicolumn{2}{|c|}{ Inclined plane test } & \multicolumn{2}{|c|}{ Rota rod test } & \multicolumn{2}{|c|}{$\begin{array}{l}\text { Electrically } \\
\text { Induced } \\
\text { convulsions }\end{array}$} & \multirow[t]{2}{*}{$\begin{array}{l}\text { Pentobar } \\
\text { bitone } \\
\text { Induced } \\
\text { hypnosis }\end{array}$} & \multirow[t]{2}{*}{$\begin{array}{l}\text { Carragen } \\
\text { in } \\
\text { induced } \\
\text { rat paw } \\
\text { oedema }\end{array}$} \\
\hline & & BGD & AGD & BGD & AGD & BGD & AGD & & \\
\hline $\mathrm{I}$ & $\begin{array}{l}\text { Normal } \\
\text { saline(2ml) }\end{array}$ & $135 \pm 0.04$ & $134 \pm 0.55$ & $32 \pm 1.43$ & $31 \pm 1.21$ & $10 \pm 1.091$ & $11 \pm 1.09$ & $110 \pm 0.34$ & $0.97 \pm 0.11$ \\
\hline II & $\begin{array}{l}\text { Erythromycin } \\
\text { (750) }\end{array}$ & $130 \pm 0.75$ & $130 \pm 0.43$ & $30 \pm 0.17$ & $30 \pm 0.033$ & $12 \pm 1.32$ & $12 \pm 1.09$ & $112 \pm 0.30$ & $0.8 \pm 0.07$ \\
\hline III & $\begin{array}{l}\text { Clarithromycin } \\
(100)\end{array}$ & $140 \pm 0.66$ & $140 \pm 0.77$ & $35 \pm 0.20$ & $35 \pm 0.25$ & $10 \pm 1.1$ & $10 \pm 1.6$ & $111 \pm 0.28$ & $0.79 \pm 0.06$ \\
\hline IV & $\begin{array}{l}\text { Azithromycin } \\
\text { (5o) }\end{array}$ & $130 \pm 1.1$ & $130 \pm 1.2$ & $30 \pm 0.33$ & $30 \pm 0.24$ & $12 \pm 0.7$ & $13 \pm 0.7$ & $107 \pm 1.1$ & $\begin{array}{l}0.50 \pm 0.04 \\
*\end{array}$ \\
\hline $\mathrm{V}$ & $\begin{array}{l}\text { Roxithromycin } \\
\text { (3o) }\end{array}$ & $135 \pm 1.3$ & $84^{*} \pm 1.1$ & $32 \pm 0.44$ & $18^{*} \pm 0.55$ & $10 \pm 0.7$ & $5 \pm 0.7^{*}$ & $\begin{array}{l}160 \pm 0.40 \\
*\end{array}$ & $0.42 \pm 0.7^{*}$ \\
\hline
\end{tabular}

BGD- Before giving drug

AGD- After giving drug* $\mathrm{P}<0.05$ 